\title{
Metaphysics and Religious Education in Primary School - Readiness for the concept of "diakoultouralismos"
}

\author{
Stamatis Portelanos \\ Assistant Professor in University of Ioannina \\ Department of Primary Education, 45110, Greece \\ Marianthi Polyzou \\ PhD Student University of Ioannina \\ Department of Primary Education, 45110, Greece
}

\begin{abstract}
The existence of "Collective Unconscious" that contains the inherent human tendency to seek truth and the will for good, composes the "intercultural metaphysics". The universality of metaphysics appears in every culture, in every person and age. Metaphysics and religiousness are connected with pedagogy, as well with psychology which is referred to the human unconscious "archetypes". The existential questions appear from childhood and find answers in the history of religious and cultural expression of all the people worldwide. Therefore, the access to the culture's ontology is elliptical, and also every educational plan for education without the metaphysical knowledge of human nature is deficient and imperfect. Pedagogy draws intercultural and "diakoultouralistic" content from any civilization and culture, in cases interested to integrate to the Curriculum topics that include experiences of mental and moral ethics. Recalling the existential and social reflection of Metaphysics and religion's history provide an opportunity for the discovery of both the substance of life and the meaning of human existence and human relations. The appropriate use of a religion's universal values eliminates the religious competition or cultural conflict and promotes the concept of "diakoultouralismos". An essential chapter of any national education is the distinction awareness of the distinction between what "seems to be" and what it finally "is", giving examples and authentic narratives of the familiar and world culture. Moreover, the memory of faiths' and beliefs' standards, which hypostatize universal virtues and values of life in connection with historical facts, are timeless hopes and inherent clues of education.
\end{abstract}

Keywords: “Diakoultouralismos”, Metaphysics, Religious Education, Primary Education.

\section{INTRODUCTION}

The postmodernity period, with the intense concern that the globalized materialistic custody and sensationalism poses, creates ways out of the cultural crisis. Sources and conveyors incorporating the social ideal and psychologically symmetrical, parallel to the aesthetic, are scaled so as to contribute to the personality development.

Utilizing methodological sources and "carriers" of liability for the current crisis of the civilization, a deep insight and investigation of the relationship between pedagogy and Metaphysics or between pedagogy and religion is proposed. The primacy of pedagogy as a Science of Humanities for the evolution of human culture is "adopted" by the world community memory file. 
Pedagogy is honored as a complex and synthetic procedure through the Collective Consciousness of human being. Universality of pedagogy is based on the "wholeness" psychophysical human being. The concept of pedagogy's universality is treated by the sciences, which explore the "seems to be" and "is" of human existence through the ages of history. The case of discovery of the real "is" of human being belongs to metaphysical philosophy, psychology and religion.

Science and Humanities develop the human consciousness. Physics and Metaphysics meet the material and spiritual, visible and invisible/spiritual dynamic element, as well as the orientation of religion addressed to the "wholeness" of human being. The power of Metaphysics is founded on the existential quests and on questions, raised even from the primary childhood. Provided the fact that pain, death, trials, love, heroism, self-sacrifice are existential questions and situations that are applied even on childhood, they require interpretation by metaphysical or religious extension. Therefore, it is reasonable that the entities of "Metaphysics" and "Religion" are integrated into the Curricula and pedagogy contents.

The development (as a narration of models-standards) of every faith's values and events, characterized by universality, justifies their existence in culture. Timeless and eternal values of humanism, from "metaphysical focus" promote interculturalism and "diakoultouralismos" and constitute essential cultural circumstances for world culture. Recognition of Metaphysics and religion as a preparatory phase for the concepts of interculturalism and "diakoultouralismos" requires the educational composition and use of all the humanities, in which the religious education based on the arch of universal values and rights is included.

\section{METAPHYSICS AND PEDAGOGY}

The management of the metaphysical child's considerations is not a negligible case for the pedagogical science (pedagogy). Metaphysics, the teacher and the "Religious subject" refer to a pedagogical trilogy, which is a target of investigation in this paper. The relevant questions posed by the relationship between pedagogy and metaphysical are: "Why issues beyond the 'natural' phenomena and sensations are of interest in schools and generally, in education?" Moreover, "From which factors and sources raises the metaphysical dimension of man and the world and which is the content of the existential issues?" "Which is the origin's power of Metaphysics and its relation to the universal values in a culture?" These are issues of substance, life and education's universal character which are worth being explored from which components are investigated and highlighted.

"Nature" is the whole cosmic reality, because it has the createdness as a common characteristic of human being. As "created" (related to createdness) is meant any real thing that does not owe its existence to himself or herself, and is not identical with the causal principle. "Nature" means both the existential universal human origins, that is the common kind of created beings, and the same/public nature of individual existences. For instance, with the concept of "human nature" are declared the common characteristics of natural "omoeideia", that means all human existences share the same nature.

Metaphysics, from its synthetic side, considers the concept of "being" a) as a creature/human being pursuing his relationship with the concept of "I am" (ontology), b) as a supreme, eternal (divine) existence (philosophical theology), c) in its relationship to the world (philosophical cosmogony) and d) in its connection to human soul, which has the potentiality to truly know it (philosophical psychology). This analysis provides information on the development of 
"diakoultouralismos". That means, it is possible, moral and philosophical issues to arise in each school, related to the core of any culture. As human nature is common to every human through its physical dimension, it also has a spiritual dimension so as to be developed. These are the "primary powers" for each human so that selects, converses, communicates and finally creates culture and civilization. Therefore, every metaphysical culture provides from the common/same human nature (humanity) values that serve common human and respected goods. As a result, "diakoultouralismos" is constituted, that is the dialogue of each culture to find a common basis: Always with respect to human life, human rights and universal values which are cultivated with the assistance of their metaphysical interpretation of each culture.

Plato shows a "diakoultouralistic" principle. Plato's three parts of the soul go against the human nature: the appetites, mind (conscious awareness), and the spirited when emphasis is placed on one, the others remain "atrophic". It's like there is a distinct division of the psyche into three different parts, that means weakening of the spiritual unity. Physical health is universally health of all body parts. Therefore, mental health refers to the health of all soul's powers, working for the virtue's acquisition. So, unity of these means symmetrical and harmonious activities for the acquisition of the virtue that is identical with the mental health. Virtue is a good, as the health of the body as well, and means beauty and good soul's condition. Contrarily to the above, evil is something like illness, ugliness and indisposition (Plato, Politeia, 444, 10DE). Interculturalism and "diakoultouralismos" cannot operate effectively when each civilization has not the culture to develop equivalents and all psychic powers harmoniously. Every country is essential not to be succumbed to the temptation of globalization replacing the unity of spirit with the irrational project (imperatives) of "I" (ego) and will.

Metaphysics concerns the displacement of the "created", the "natural" (based on senses) and the "attitude" of the spirit (ecstasy) beyond the hackneyed and useful. Metaphysics arises from the moment every human is wondering about the first cause (reason) of things, has a strong desire for the truth of life, the acquisition of endless knowledge, the struggle and sacrifice for eternal/universal values and the meaning arising from the ontological superiority of human nature. Man is the only "being" (existence) in nature who wonders about the limits of nature. Every human operates between autonomy and heteronomy. Autonomy differs from the metaphysical freedom (although it is required for the existence of autonomy), defined as action regardless of causal order of nature (Baggini \& Fols, 2014: 41). Thus, Metaphysics constitutes a universal phenomenon, for each culture and civilization and with this as a common cultural narrative, Metaphysics is recommended as a tool of "diakoultouralismos".

Man raises questions and explores the possibility of a meta-physical reality. Only, man of the rest of God creation puts forward evidence and experiences, or desires the existential freedom from the conditions and restrictions of nature (Giannaras, 1993: 213). Is Science able through the investigation of the natural world to export or to propose eternal values going beyond the autonomy, the three-dimensional space, the fourth dimension and the biological feasibility? Wittgenstein $(1978,7 / 8: 3.262)$ notes that: "If there is a value to be of value, must be out of everything that happens and have-so". Unconscious, as proposed by the Psychology provides what is called as "unexplored space" for the metaphysical investigations. Many times, we trust the inherent tendency of the human instinct to do well.

When we say that "the world has everything" we mean that everything can happen in human life: The necessary, possible, unnecessary, and the impossible or "unthinkable", as well. The concepts mentioned below are not incidentally created: Natural, metaphysical, supernatural, 
finite and infinite, eternal, impossible and possible. These are concepts deriving -firstly- from the language of restless and searching human spirit and its unimaginable dimensions. Natural world has a beginning and an end, the metaphysician world has no beginning or end, because it starts with other questions ("why") and invisible and irrational conditions, that means metaphysician world is not subordinated to rationality. However, since both concepts concern human nature and are deriving from it, this means that physical and metaphysical are together and coexist everywhere inside the world's unity/universality and in the whole God Creation.

The perception that every human is inseparably connected with nature creates problems in the practice part of free will in order to interpret the world via metaphysical, philosophical and theological reports of the past. "By which methods and circumstances the personality of the child is learnt, how to overcome weaknesses and to 'infiltrate' to the incomprehensible and to put limits on the use of the material world, freedom and needs?" (Ellul, 2006: 46). The modernist rationalism, despite his avoidance of the "holy" in the world, failed to eliminate the people's tendency to investigate the metaphysical, and did not manage -using the knowledge and the sciences research- to conceal the existential problems or the ecological anxiety.

Modernist thought, according to one version, is the only one that has arrested a world demystified, followed by the separation of religion from morality and civilization. However, according to another concept, modernity was influenced by the rationalism of classical Greek ancient times and the sacred (holy) continued to exist as a concept, specifically as a fundamental principle of the world (Kokosalakis, 2002: 64). On another way, "cosmogony" is interpreted through logic or via Metaphysics. Pedagogy, in the distinction between "Godcreator" and "Human-operator", contributes to social bliss and equality. If human, when in everyday life and in his vocabulary, contains the "inconceivable" -as a concept-, then the metaphysical is not trapped in the building materials of the natural world. If death beats life, then we are not inheritors to a category of historical civilizations, having eternity as a desire, such as the Egyptian, Greek and others (Barilier, 2004: 506). These civilizations survived because they lived together, learned to every human the metaphysical, divine and supernatural, which are still reflected in their funerary monuments. It should be noted that our house and our residence place are not a material object, a "machine to be inhabited". They represent a "universe" that every human builds imitating the divine creation/God Creation (Eliade, 1965: 55).

The distinction between the concepts of civilization and culture is likely to shape specific circumstances for Metaphysics and Religion, inside school. It has been found, based on the existing phenomena of violence and antagonism in the society, that each civilization is possessed of barbarism and generates terrorism without culture/education, with a reliable content. Skepticism arises, in cases when the modern civilizations can survive, find meaning in the monistic conception of individuality, in the "cold logic", utilitarianism and in the selfcriticism without comparison to past times, or when power arrogance, accumulation of material wealth and stress/anxiety, imposed by technocracy, dominate in the civilizations. According to Ellul (2006: 47), a question is raised "Does the alienated man attributes to Science a role, meaning circumstances and a lifestyle deriving from the moral or divine element?" However, "religion's and policy's desocialization", characterized by their ideologization and the disunion between pedagogy and education, causes problems during their practical adjustment, in linking theory and practice.

Modern and postmodern Metaphysics may consider its existence via three points/elements: a) The current reality makes people be pessimistic, however the metaphysical hope for humanity 
will come from the reflection and regrouping of its powers, b) the distance of everyday political life and culture/education that creates inequalities, requires excess and c) education should be related to Metaphysics because values neither can be unrelated to the diachrony nor being shrunk from the logic or science. Besides, in terms of science the future is based on possibilities and not definitive, since knowledge and the "end" are "endless, interminable", due to the fact that they are connected with the spiritual dimension of every human. The internal knowledge assists "know thyself", which is the content of culture and the Metaphysics of psychology as a teaching component. Quantum mechanics asserted in the same nature of things, a probabilistic character that is not a measurement imperfection and lack of sufficient computational precision, though gives a certain way of physical reality (Oikonomou, 1990).

With the approach of universality of every human's spiritual sustenance, the unconscious and the conscious give position on issues not related to science, such as archetypes, essence, meaning of life, faith, prayer, eschatology, etc., which are touched at Metaphysics, philosophy, religion and theology. These are investigated through a holistic approach of anthropology, since mind and the whole spiritual dimension of the human studies these subjects beyond "natural" and perceptible. In the parable of the "Rich Fool", who acts focusing only on "ego" (himself) and his senses, with his avarice and greed, God is shouting into his consciousness: "Now that you go away from this life, those who have prepared, to whom do they belong?". Unlike the divisive senses' perception, the Spirit acts jointly to itself, time, and to the relationship with the world.

It is accepted that through physiology or sensationalism, the procedure in human life to have a beginning (birth) and a biological end (death). However, via Metaphysics that is focused on spiritual existence of human being, the path inside himself, has neither beginning nor end. The child's and every human's necessity to believe in something beyond biology is so remarkably resilient, so there are some religious beliefs that persist in their historical and cultural uniqueness. But the belief in Supernatural is sometimes dangerous because it is associated with less profound -and clearly irrational beliefs- (alien abductions, mentors of past lives, telepathy, astrology, necromancies, ghosts, etc.).

In times of postmodernity, human's reference to Metaphysics and religion is a central tool in a world's and history's vision about the daily struggle between good and evil. The extent of political analysis, based on the criteria of culture and "ruptured" section within social entities, includes some new risks such as: The axis of evil, terrorism, weapons of mass destruction, etc. However, there are comparable data for the review of the current culture. Civilization's and culture's crisis is analyzed in Western societies by many intellectuals who draw on Greek philosophy and its evolution, in history and in the eternal/universal values of Christianity (Corn, 2006: 111-112). Criticism made in a civilization requires as a condition, elements/data of reduction and interpretation of life to indicate when in a society crisis, recovery or regeneration exists.

\section{COLLECTIVE UNCONSIOUS - RELIGIOUSNESS}

In the question, based on a human-dedicated criterion about "Which is the starting point for the metaphysical and existential human issues?", the answer is clearly given by the classical philosophers. The concepts of "Metaphysics", "unearthly" and "beyond" of human and God, are for Greeks intrinsically inherent and implanted in their deeper ordinary/earthly reality. Understanding the underlying relationship between Metaphysics and religion, is plainly 
associated with the existential questions of human nature, which are unconsciously implanted in every human and remain to be answered.

Metaphysics is "implanted" deep inside every human. Aristotle uses the Greek verb form "тв́ tendencies like "bravery" (Politics: 310d6), the "love power for the truth" (Plato, Filivos: 58d), love for "good" (Aristotle, Filivos: 64a) and like for "nice" (Plato, Politeia: 403a7), the disgust we feel towards injustice (Plato, Gorgias, 479d6) etc. are "implanted" in ourselves, and these are the unconscious side of human existence. Therefore, there is a basis in every civilization, deriving from the collective unconscious, in a way that the local culture and "diakoultouralismos" are consolidated on each civilization. A culture may contain the same intangible values with other cultures. For example, Hesiod writing about injustice mentions that it is bad for both the modest mortal human being, and for the "noble"/aristocratic, the higher one in the social hierarchy. Finally, the revelation of justice overcomes injustice (Hesiod, 2001: 210-220). The predominance of justice is a desire of every man, of any culture. As a result, a universal virtue/value, when grown from a civilization, is likely to become an element of "diakoultouralismos", that is an element of communication and inter-embracing to another culture and civilization. The ancient tragedies are a country's cultural constructions, which through their aims and scope teach them, over time/diachronically, and become actors of "diakoultouralismos". Uniqueness of every culture is evaluated by the universal community and organizations and becomes a World Heritage Site.

The "seed" of religiousness is planted in the unconscious of the human being, in order to be cultivated, but there is also responsibility for the circumstances connected to education. Metaphysics and Religion have "roots" in the collective unconscious. In every man, from the time of his birth, a "seed" with refined feelings, deriving from morality is implanted. According to Hegel (2011) human being is "implanted" with a sense of moral ( "no man is from its nature bad"), which goes beyond mere sensation, "The aim of education is these nice 'seeds' not to be decomposed', but contrarily from these 'seeds' a true sensitivity for moral ideas and feelings to be created. However, Religion is not the first that can 'throw roots' in this psyche, this has to find 'cultivated land to thrive"' (Hegel, 2011: 38). Consequently, the family environment, other school subjects and teachers contribute or "shade" the innate "a priori" metaphysical tendency for ethics and development of religious sensitivity.

The "Collective Unconscious" is the base of "diakoultouralismos". The "Collective Unconscious", according to Carl Jung, contains characteristics which are not experienced individually by the human, but these are inherited from a deeper and wider dominion. The features of "Collective Unconscious" are the progenitors' special characteristics (progenitors; cultural identity), which successively are transferred from generation to generation, expanding the heredity. Thus, the "intergenerational tree" of humanity is created, which is like a database infused in every human being. There are impersonal powers established in the unconscious. A bitter eternal/diachronic finding, existing in today's competitive "society", is "homo hominis lupus" (human as a wolf). When people behave as a crowd, owning wild instincts, then they become insignificant. So, without any consciousness cultivation, man declines unconsciously in a morally and intellectually inferior level. The disruption of the relationship between unconscious and conscious creates an imbalance in human life.

Through the collective unconscious, human is eminently a spiritual nature and invited to become such an existence, by implementing these "imprinted" authorities inside his consciousness. Neurosis and crime are the consequences of repelling these principles. Karl 
Jung named his conception of the Collective Unconscious "archetypes" (including universal and archetypal processes) and admitted that they constitute the keystone of conscious life. The symbols are used in order -through them- the consciousness and the logic to be expressed. Dominant symbols, such as "mother" or "father" or "God" are a priori registered in the collective unconscious and then they are expressed via the word-symbol "mother". Our thoughts are always symbolic. This means that thought works with the mediation of symbols /signs. There is a gap between image and perception. This is the human characteristic.

According to Carl Jung, Jesus Christ is the archetype of the archetype "God", because materializes, "symbolizes" in reality -as God and Man- the archetype "God" (Nisiotis, 2006:107117). When somebody refuses to accept the God symbol, that does not mean he denies the archetype transmitted to consciousness. Nisiotis (2006) writes that when Nietzsche said that "God died", it should be understood that the symbol "God" was lost, but not the archetype of "God". That is, consciousness is archetypal, driven by the archetypes of the Collective Unconscious. Carl Yung has shown that people who have had "neurosis" (personality segmentation due to the existence of complexes which cause disorder in the relationships with themselves and others), had experienced a violent separation from the "God archetype". It is reported, that in 35 cases, patients regained their mental balance with the restoration and realization of the archetype "God". As a result, the connection between "God archetype" and Jesus Christ, which in fact invades in the humanity's history as God-man, is crucial. According to Jung, Jesus Christ is the archetype of the archetype "God", because materializes, "symbolizes" in reality -as God and Human- the archetype “God” (Nisiotis, 2006: 107-117).

Science is not able to suggest a belief, based on which moral values could find a new foundation of spiritual values. Science, focused on her research subjects and rejects any equation between belief and knowledge (Monod, 1999: 46). Science is objectively a verifiable knowledge, while belief concerns the individual perception/belief that the person selects, as an answer to metaphysical questions, without the need for evidence analysis (Giannaras, 1993: 80-81). The" unknown part" of the unconscious or of the emotion is obviously infinite both in logic and senses. Therefore, only by factors outside of unilateral mental beliefs, the infinite and the eternal are gained. "We gain something that is determined with difficulty, located in the center not only of religion, but also in the center of art, poetry and of all higher aspirations of human emotion" (Murray, 1996: 18-19).

In psychiatry, an important question is raised: "How preferable and relieving is the religious solution to the 'meaning problem' compared to the most rational, but empty message of nature, reminding us of our infinitesimal space occupied in the Universe and in the large chain of events?" (Yalom, 2002: 27-28). He is then referred to a cartoon/sketch in which a number of different species are presented in separate squares: A worm, a fish, a bird, a snake, a cow. All these creatures murmured the same refrain: "Food, survival, reproduction - food, survival, reproduction". In the end of this picture there was a man having the "Thinkers attitude". He was muttering to himself: "Why, why?" All life creatures (species) perceive what it is for. Only humans do not mean to perceive the meaning and accept it, and because of this, we make civilizations and have demands and then we set higher/superior purposes or aims at our lives (Yalom, 2002: 27-28). Language, social institutions, Religion, Art, knowledge, Science, and generally the existence of civilizations is a purely human creation that has nothing in common with the animal kingdom. 
Metaphysics begins when, after the connection between our senses and the world, we are trying to find out their meaning. "Antimetaphysics" is the persistence in the question of "what", in the quantity and not in the question of "why" and in the spirit's quality advanced by Metaphysics. This procedure is difficult and laborious for every thinking person, and the discovery of a large monumental treasure.

School and classrooms are not just walls and desks. It is life itself, in physical and metaphysical dimensions and as Rilke has noted "going through childhood means to live a thousand lives before 'one'". That's why in the Minoan religion, Greek Gods are shaped with a child's form, because children are the "bridge" connecting people. Gods - children (meant: having the form of a child) are protectors and represented in art. The renowned sons of Jupiter ("Zeus kouros"), Gods of the hearth, are often called masters ("anakes") (Nilson, 2008: 40-41). God in Christianity is revealed in his incarnation as a child. When Jesus Christ speaks as a teacher, advises adults, who were in front of him to see him and hear his calls, to give priority to the children. That means, it is very important that a content of specific culture with its religiousness and standards / archetypes is transferred in Primary Education.

Beyond the concepts of "Have", "Know", "Can", that the adult generation teaches, there is a genuine desire of the child to express the verb form "I am". The meaning arises from the person, not the idea. Nowadays, who are they that invite the child and learn him "I am", so that each child is able to announce his identity by linking it to his origin and culture? For example, Jesus Christ calls himself at first verbal person "Truth". Jesus Christ, as a reference face advises adults to leave children to approach their Origin, the one that derives from "Being". The anthropology without ontological access to "Face" focuses on egocentrism and in the theorizing or biological approach of "Truth". God reveals himself with the phrase "I Am who I Am". This present tense ("I Am") and the imperative "let" means: Christ unceasingly invites children to experience "What I am" (Truth), so as to find their spiritual identity, based on their origins, when children are using themselves the verb form "I am" (Dolto \& Severin, 2002: 38-39). This is a challenge of openness to innocence through an educational process ending with the entry to the child's life of eternal "I am" joined with "eternal Being".

Each child has a pure and spiritual part of receiving new educational beliefs. For this reason, even in childhood manipulation exists related to religious or political indoctrination, ideological directions carried out authoritatively, fanaticism, aesthetics and other addictive dependencies, during the process of consciousness development. The "theological pillars" of Christianity: Ontological, anthropological, ecological, psychological, pedagogical, which jointly shape the awareness of each person's culture (meant his country's culture and identity) contribute to the global, careful observation of self and of the world generally and in the provision of intercultural relationship and communication, too.

The unconscious and the under development consciousness of "ego" is the area of education. According to Rilke, everyone is deep inside like a Church, and the walls are decorated with holy/celebratory hagiographies. In early childhood, although access to this magnificence is free/public, it is still dark to see the images. Afterwards, as the room begins to be illuminated by various socio-pedagogical factors, then incorrect experiences are covering one wall after another. And some are evolved in life the way they think, without even to suspect the old magnificence "under the sobriety of poverty" (Baer, 2009:191). 


\section{Proposed}

\section{CONCLUSIONS}

1. Utilization of metaphysics' and religion's capacity and dynamics related and addressed to the knowledge of anthropological and ontological human dimension.

2. "Projection" of the Collective Unconscious on the religiousness and the highlighting of "archetypes", as well as the formation of consciousness.

3. Awareness and approach of human nature's universality through religious education.

4. Awareness of social, inter-social, intercultural and a "diakoultouralistic" dimension of metaphysics and religion.

5. Development of the indigenous religious tradition and through this, the creation and formation of an intercultural and "diakoultouralistic" consciousness.

6. Recognition of Metaphysics and religion as a preparatory phase for the concept of "diakoultouralismos". Communicating universal values of any religion to every child, which can contribute to the indigenous culture and the vision of interculturalism and "diakoultouralismos" are considered necessary.

\section{References}

Baer, U. (anthology). (2009). The Wisdom of Rilke. (A. Nikolakopoulou, trans.) Athens: Patakis.

Baggini, J. \& Fols, S.P. (2014). The Ethics Toolkit: A Compendium of Ethical Concepts and Methods. (K. Theologou, trans.) Athens: Kastaniotis.

Barilier, E. (2004). Nous autres civilisations... Paris: ZOE.

Corn, G. (2006). La question religieuse au XXIe siècle. Paris: La decouverte.

Dolto, F. \& \& Severin, G. (2002). Les Evangiles et la foi au risque de la Psychanalyse. (E. Kouki, trans.). Athens: Estia.

Eliade, M. (1965). Le sacre et le profane. France: Folio essais, Gallimard, p. 55.

Ellul, J. (2006). La foi au prix du doute. Paris: La table Ronde.

Giannaras, X. (1993). Postmodernity Metaphysics. Athens: Domos.

Hegel, G.W.F. (2011). Lectures on the Philosophy of Religion. (S. Giakoumis, trans.). Athens: Eridanus, p. 38.

Hesiod (2001). Works and Days. Athens: Zitros, pp. 210-220.

Kokosalakis, N. (2002). Traditional Religion and Society in Late Modernity, in: Religion and Politics in Modernity. Athens: Kritiki, pp. 56-92.

Monod, J. (1999). From biology to ethics. (S. Sfendourakis, trans.) Athens: Sinalma.

Murray, G. (1996). Five stages of Greek Religion. (E. Papadopoulou, trans.). Athens: Iamvlixos.

Nilson, M.P. (2008). History of Greek Religion. (K. Papathomopoulou, trans.). Athens: D. Papadimas.

Nisiotis, N. (2006). Psychology of Religion. Athens: Maistros.

Oikonomou, E.N. (1990). Physics today. I. The foundations. Heraklion of Crete: University Press.

Plato, (1993). Politeia. Athens: Kaktos, 444, 10 DE.

Wittgenstein, L. (1978). Tractatus logico-philosophicus, (T. Kitsopoulos - Z. Loretzatos, trans.) Ed. Papazisi, “Deukalion” 7/8: 3.262.

Yalom, I. (2002). Religion and Psychiatry. (E. Andritsanou - J. Zervas, trans.). Athens: Agra. 